\title{
Nanotechnology of "intellectualization" of energy accounting and of suppression of fire-energy harm in engineering systems of residential buildings. Part 2
}

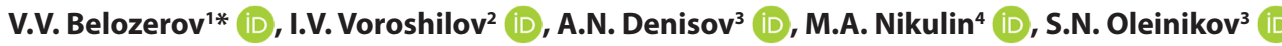 \\ ${ }^{1}$ Don State Technical University, Rostov-on-Don, Russia \\ ${ }^{2}$ Krasnodar Compressor Plant LLC, Krasnodar, Russia \\ ${ }^{3}$ Academy of the State Fire Service of the EMERCOM of Russia, Moscow, Russia \\ ${ }^{4}$ State Agrarian University of the Northern Trans-Urals, Tyumen, Russia \\ * Corresponding author: e-mail: safeting@mail.ru
}

\begin{abstract}
Introduction. At present, both abroad and in Russia, accidents, fires and explosions in the engineering systems of multiapartment residential buildings and individual residential buildings have become more frequent. At the same time, the "creators" of automated systems for monitoring and accounting of energy resources (ASKUE) did not attend to the solution of the problems of safety of engineering systems, since their goals were exclusively commercial tasks - "digitalization" of energy consumption metering and detection of illegal consumption of such sources. Therefore, in this article, an attempt is made to "eliminate clutter" in the automation of engineering systems in the residential sector. Methods, models and tools. Based on the analysis of engineering systems of multi-apartment residential buildings and individual residential buildings, as a result of the functioning of which not only the delivery of life support resources (gas, cold and hot water, electricity, communications, etc.) is carried out, but also fire-energy and environmental harm occurs, a methodology has been developed for the "intellectualization" of the means of accounting for the supplied resources, for the purpose of diagnosing and suppressing fire-energy harm using modern nanotechnologies and, thus, preventing accidents, explosions and fires in the residential sector. Results and discussion. The methodology of "intellectualization" is based on the dialectical unity of benefits and harms from consumed energy resources (electricity, domestic gas, hot and cold water), as well as to carry out a systemic synthesis of nanotechnologies and means of "detection and suppression" of fire-energy harm. The novelty of the research is protected by RF patents. Conclusion. The proposed approach makes it possible to "eliminate the disorder before the automation" of engineering systems of multi-apartment residential buildings and individual residential houses, by "intellectualizing" metering devices and optimizing nanotechnologies for suppressing fire-energy harm which leads to socio-economic losses.
\end{abstract}

KEY WORDS: automation, engineering systems of buildings, fire-energy harm, diagnostics of hazardous factors of fire and explosion, electric meter-detector, reactive power compensator, membrane air separator, thermomagnetic air separator.

FOR CITATION: Belozerov V.V., Voroshilov I.V., Denisov A.N., Nikulin M.A., Oleinikov S.N. Nanotechnology of "intellectualization" of energy accounting and suppression of fire-energy harm in engineering systems of residential buildings. Part 2. Nanotechnologies in Construction. 2021; 13(3): 171-180. Available from: doi: 10.15828/2075-8545-2021-13-3-171-180.

\section{INTRODUCTION}

Th recent years, cases of natural gas explosions in residential buildings have become more frequent in Russia. Thus, according to Rosgazifikatsiya, about 200 different incidents related to the use of gas occur annually in the residential sector. At the same time, the number of explosions and socio-economic losses from them are increasing (Fig. 1), and Rostekhnadzor blames the incident on the human factor, dividing the consequences into the following categories - damage and collapse of buildings (destruction of housing stock), death and injury people, material damage, psychological impact on the population, environmental pollution. In the overwhelming majority of cases, the epicenters of the explosions were located inside apartments. At the same time,

(c) Belozerov V.V., Voroshilov I.V., Denisov A.N., Nikulin M.A., Oleinikov S.N., 2021 


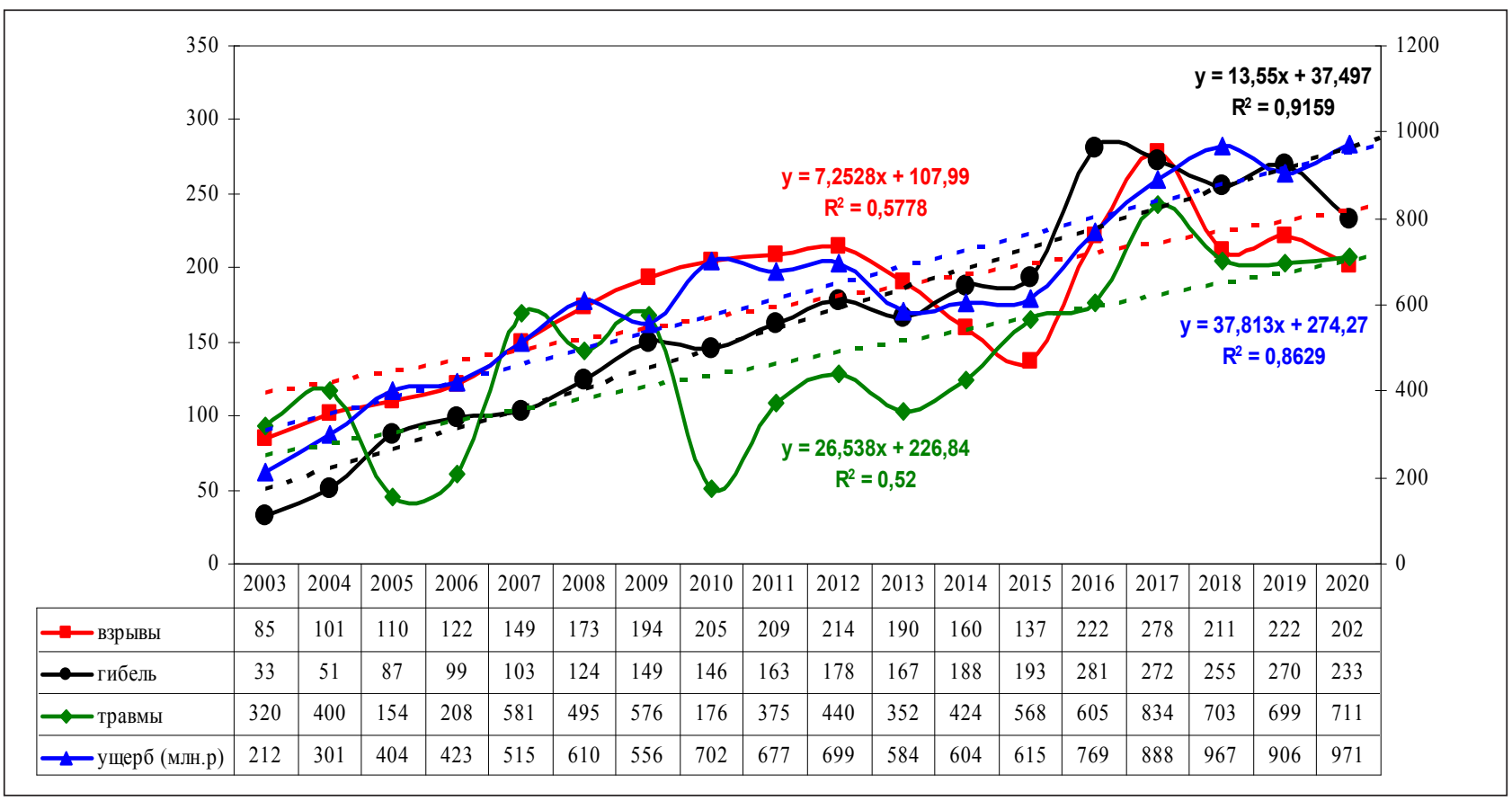

Fig. 1. Graphs of the number of gas explosions, injuries, deaths and damage in the residential sector of Russia

about $80 \%$ of the victims were poisoned by combustion products and $20 \%$ suffered from gas-air mixture explosions and fires [1].

From a number of fire-technical examinations it follows that some explosions and fires in the residential sector occurred due to gas leakage from external gas pipelines, by leaking into the apartments of the first and last floors and subsequent explosion / ignition, from sparking in wiring accessories [2].

An obvious solution to prevent domestic gas leaks is to install a gas meter with a solenoid valve (Fig. 2) at the gas inlet to an apartment or individual residential building, which cuts off the gas supply in the event of a leak [3],

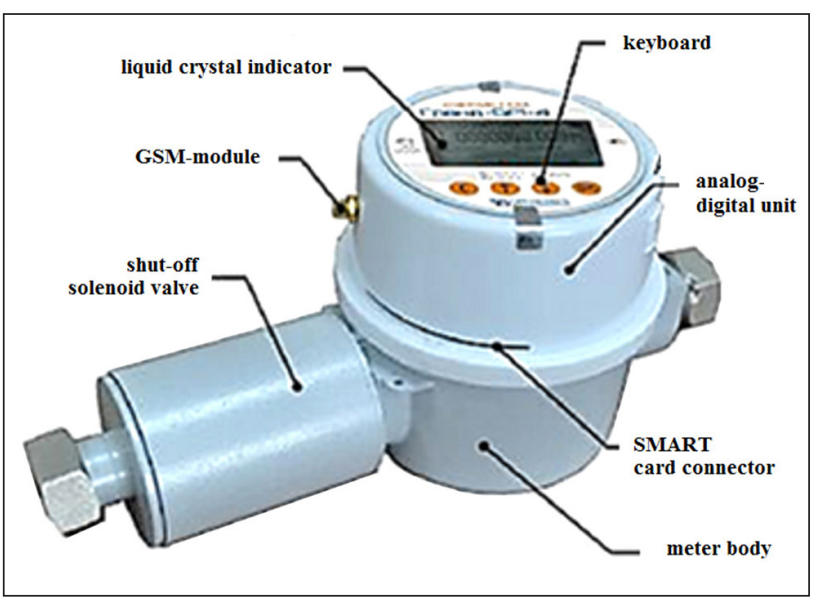

Fig. 2. Gas meter Grand-SPI with a leak sensor and a solenoid valve as well as the addition of an electric meter - detectorsuppressor of fire-electrical harm (EMDS FEH) with a sensor for household gas [4], in order to detect such a leak and prevent an explosion by turning off electricity in an apartment / individual house using a reactive power compensation unit (RPCI) EMDS FEH (Fig. 3), which turns such a combination into an electric-gas-meterdetector-suppressor FEH (EGMDS) [5]

Grand SPI (Fig. 2) is designed for commercial metering of consumed natural gas by individual consumers, and includes [3]:

- gas flow converter - jet generator and piezoelectric element;

- built-in temperature sensor;

- built-in pressure sensor;

- analog-digital unit;

- computing unit;

- interface block;

- an autonomous power supply element;

- GSM / GPRS modem (depending on the version);

- gas leakage sensor;

- shut-off valve (depending on the version);

- meter body with connecting pipes.

Data exchange of a gas meter and control of an electromagnetic shut-off valve from external devices, with EGMDSFEH, in particular, can be carried out by means of a built-in GSM modem or wires from a technological connector [3].

In this case, it becomes possible to determine already the fire-energy harm with the dimension MJ according to the formula [5]: 


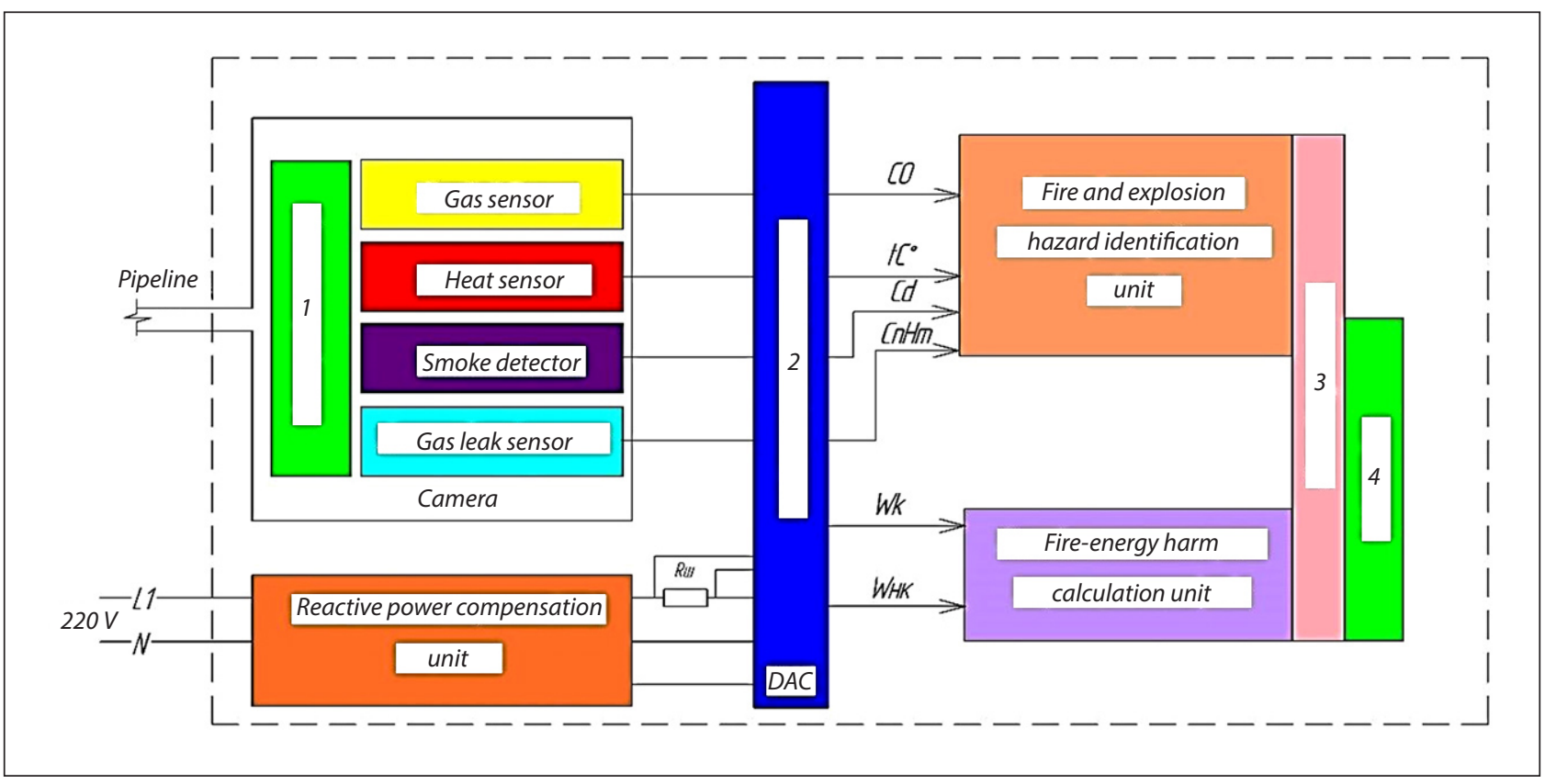

Fig. 3. Block diagram of EGMDS FEH with RPCI

$$
\mathrm{FEH}=\mathrm{k}_{\mathrm{J}} \cdot\left(\mathrm{P}_{\mathrm{D}} \cdot \mathrm{W}_{\mathrm{D}}+\mathrm{P}_{\mathrm{ND}} \cdot \mathrm{W}_{\mathrm{ND}}\right)++\mathrm{q}_{\mathrm{G}} \cdot \mathrm{P}_{\mathrm{G}} \cdot \mathrm{W}_{\mathrm{G}},
$$

where FEH - fire-energy harm for time $\mathrm{t}, \mathrm{k}_{\mathrm{J}}-$ coefficient of conversion of kilowatt / hour to Joule $(3.6 \mathrm{~mJ})$; $\mathrm{q}_{\mathrm{G}}$ - calorific value of gas $\left(35 \mathrm{~mJ} / \mathrm{m}^{3}\right) ; \mathrm{P}_{\mathrm{G}}$ - the probability of fire from gas appliances; $\mathrm{W}_{\mathrm{G}}$ is the volume of consumed gas, $\mathrm{P}_{\mathrm{D}}$ is the probability of a fire from electrical appliances with high-quality electricity; $\mathrm{W}_{\mathrm{D}}$ - the volume of high-quality electricity consumed by electrical appliances; $\mathrm{R}_{\mathrm{ND}}$ - the probability of a fire from electrical appliances with low-quality electricity; $\mathrm{W}_{\mathrm{ND}}$ is the volume of low-quality electricity consumed by electrical appliances.
However, EGMDSFEH will not be able to protect an apartment or an individual residential building from fire and explosion if they arose not from electrical appliances and their own gas leak, but, for example, from careless handling of fire or a smoldering cigarette butt, as well as from the leakage of household gas from the outside (external gas pipeline, neighboring apartment, etc.). Only the use of gas fire extinguishing installations (not water!), Which lower the oxygen concentration in the protected premises, allows suppressing the fire without damaging furniture, appliances and household items [6].

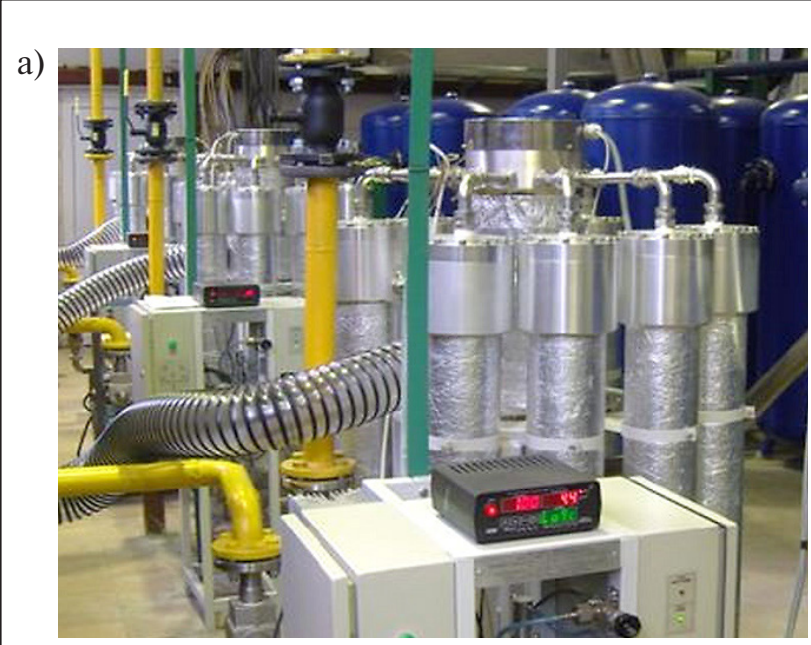

b)

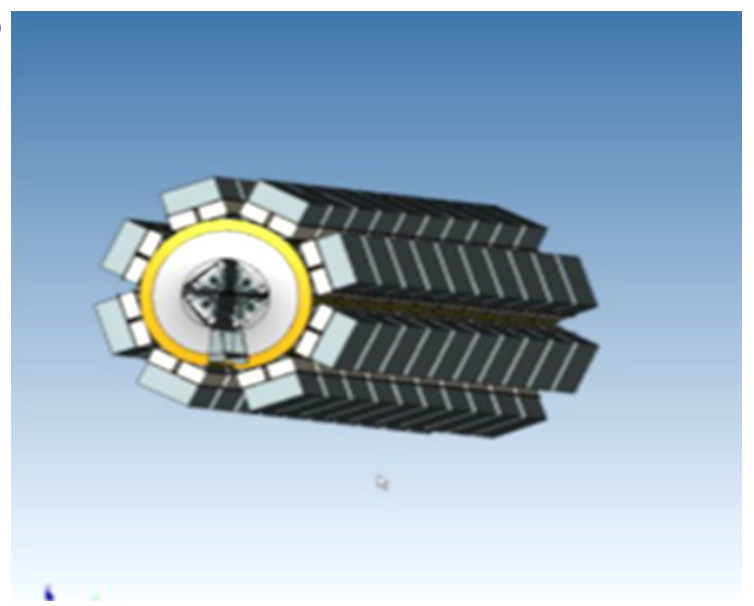

Fig. 4. Membrane separator of air ("a") and thermomagnetic separator of air ("b") 
Therefore, the idea arose to use the pipeline of the aspiration system to supply nitrogen to the protected premises, for example, by joining the EGMDSFEHwith a membrane (Fig. 4 "a") separatorof air (MSA) or with a thermomagnetic (Fig. 4 "b") separator of air (TMSA), because such integration will allow for the complete suppression of the determined FEN and to detected hazardous factors of fire and explosion (HFFE), without causing damage to devices and household items, which was protected by RF patents [7, 8].

Thus, the final task in the "elimination of disorder" in the automation of the life support of the residential sector is the integration of EGMDSFEHwith nanotechnologies for gas separation of air and with "smart" meters of hot and cold water [9] into a local automated microsystem for diagnostics and accounting of consumed energy resources in the residential sector [5], incl. with the suppression of communal accidents arising in this case, but also FEH and HFFE with the help of an electric-gas-water-meterdetector-suppressor (EGWMDS).

\section{RESULTS AND DISCUSSION}

The system synthesis of the optimal model of EGWMDS led to the following obvious solutions.

Firstly, the devices "Grand SV TLM" were selected as hot and cold water meters (Fig. 5), designed to measure volumes of cold drinking and hot water according to the standards (SanPiN 2.1.4.1074-01 and SanPiN 2.1.4.2496-09) having [9]:

- flow-through measuring chamber with impeller and temperature sensor;

- analog-digital unit with liquid crystal display (LCD), keyboard, pulse input / output and GSM communication channel;
- external shut-off valve (controlled via interfaces: MODBUS RTU, GSM, GPRS, Bluetooth).

Secondly, such an integration required the introduction of a more powerful controller (3) with modules (3.13.3) and input-output ports (3.4-3.10) into the EGWMDS (Fig. 6).

Thirdly, EGWMDS can be easily unified with the help of an external air separation unit (ASU), since consists only of pipelines and solenoid valves [6]:

- for apartments in high-rise residential buildings where there is no gas supply and three-phase power supply of apartments, and an MSA with additional solenoid valves and a starting block for its electric compressor, including a reserve diesel engine (Fig. 7 "a"), is installed on the technical floor (Fig. 7 "b") or in the basement, with the appropriate" wiring "of nitrogen and air pipelines in apartments in parallel with the water supply pipes (Fig. 7 “c"),

- for apartments in multi-apartment residential buildings, where gas supply and single-phase power supply are used, and MSA can be used similarly to high-rise buildings, or TMSA, which is installed next to EGWMDS in the hallway, because algorithms for its functioning and ASU operation remain unchanged,

- for an individual dwelling house (Fig. 8), where TMSA and / or MSA can be used.

Unification allows the production and installation of the specified EGWMDS:

- with a gas meter,

- with one or more water meters,

- with RPCI for three-phase and / or single-phase power supply,

- with TMSA for apartments and small individual houses,

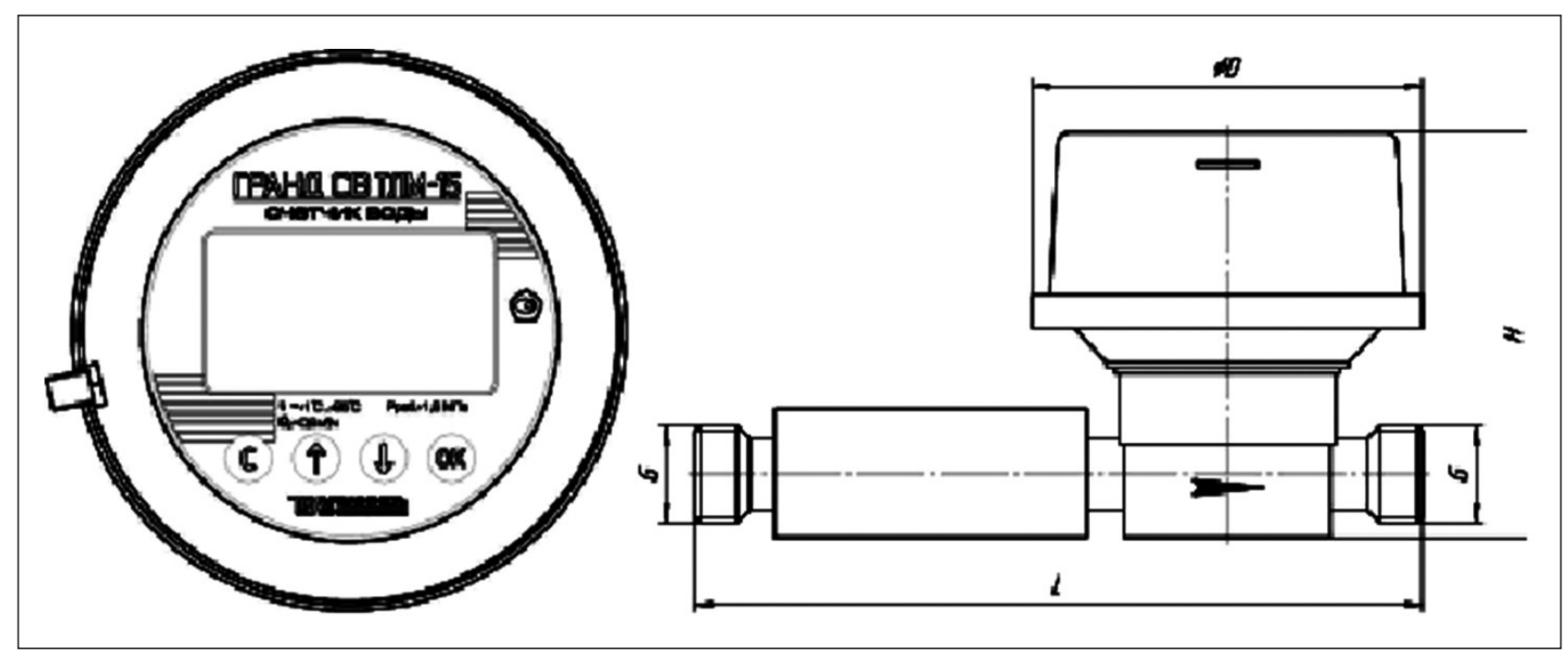

Fig. 5. Meters of cold and hot water with solenoid shut-off valves 


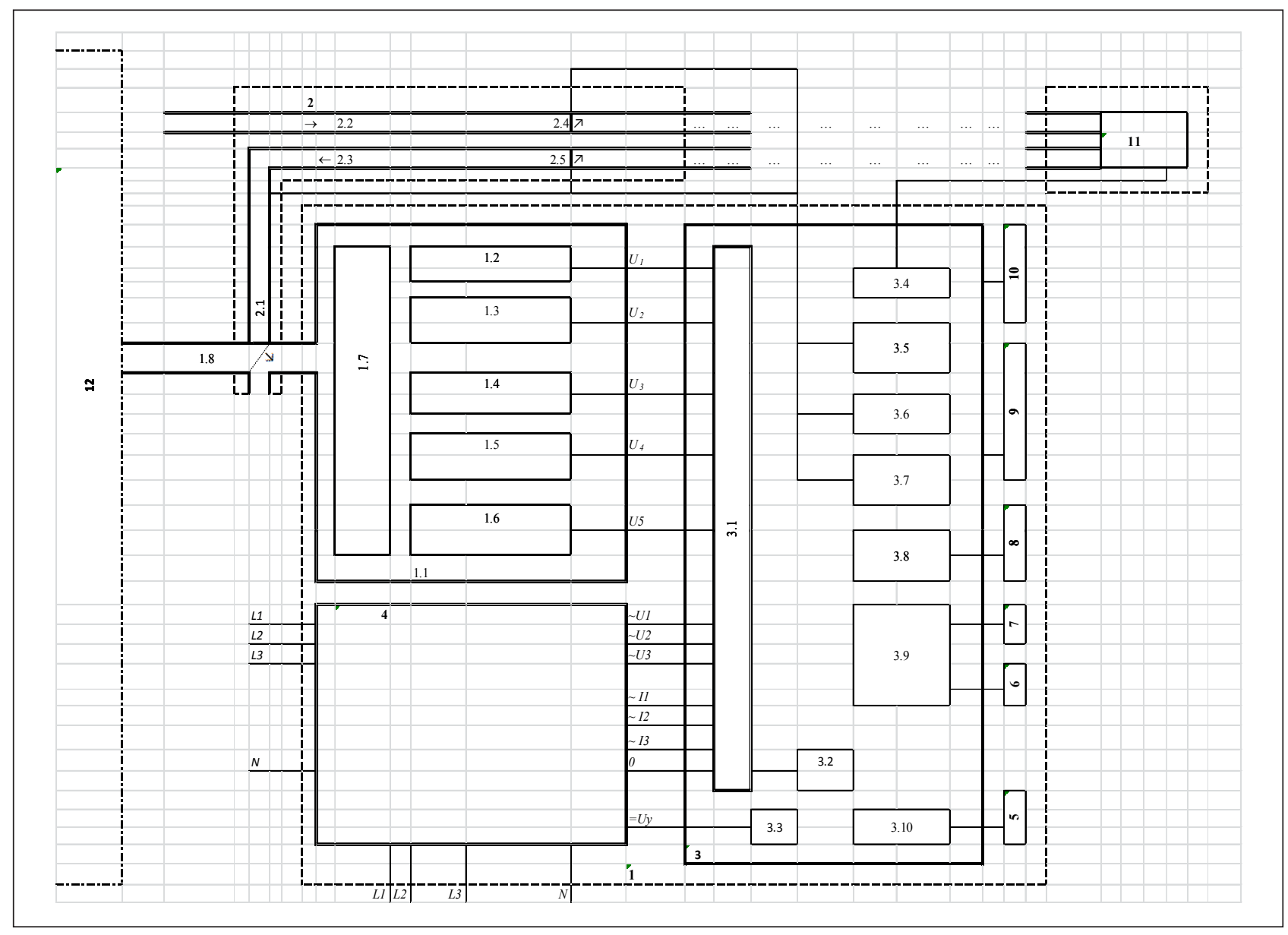

\section{Fig. 6. Block diagram of EGWMDS}

- with MSA for multi-apartment and high-rise residential buildings.

Thus, the structure and algorithms of the EGWMDS, which are described below, do not depend on its specification.

At the entrance to ASU (2), which is powered by EGWMDS (1) and its accumulator (9), solenoid valves $(2.4,2.5)$ are installed, through which pipelines $(2.2,2.3)$ are connected, going along the risers of the building next to the water supply pipes and drainage from the MSA (11), installed in the technical floor / basement and switched on by the controller (3) through the input-output port (3.4), upon detection of the HFFE in the protected premises (12) using the EGWMDS (1).

At the same time, through the RPCI (4), the electricity in the apartment / house is turned off and the camera (1.1) with the electric fan (1.7) and sensors (1.2-1.6) with the help of the electromagnetic valve (2.1) is switched to detect the HFFE in the room where the EGWMDS is installed, and also, the notification of residents about evacuation through the liquid crystal indicator with piezomodule of audio-video information (LCIP-module) (10) is turned on.
From the air sucked by ASU (2) from the room where it is installed, through the air duct (2.2), MSA (11) separates oxygen, which is removed either into the ventilation system or outside the building, and the separated nitrogen returns into roome through the nitrogen duct (2.3) and pipelines of the aspiration system (1.8), which ensures a rapid decrease in the oxygen concentration in the protected rooms (12) to a level at which combustion or explosion is impossible, and EGWMDS (1) continues to register the HFFE, since the chamber (1.1) remains connected by means of the solenoid valve (2.1) to the part of the pipeline of the aspiration system (1.8), registering and storing in memory the values from the sensors of temperature (1.2), of smoke content (1.3), carbon monoxide concentration (1.4) and domestic gas (1.5) and oxygen (1.6) in the room (as a rule, in the hallway at the front door), where the EGWMDS is installed, for comparison and identification of changes occurring in the rooms (in the absence of the HFFE), and the moment of the end of the HFFE suppression process, at which the controller turns off the MSA [5.6].

The use of a GSM radio modem (5), connected through the input-output port (3.10), makes it possible to transfer data on the consumption of "quality resources" 
a)

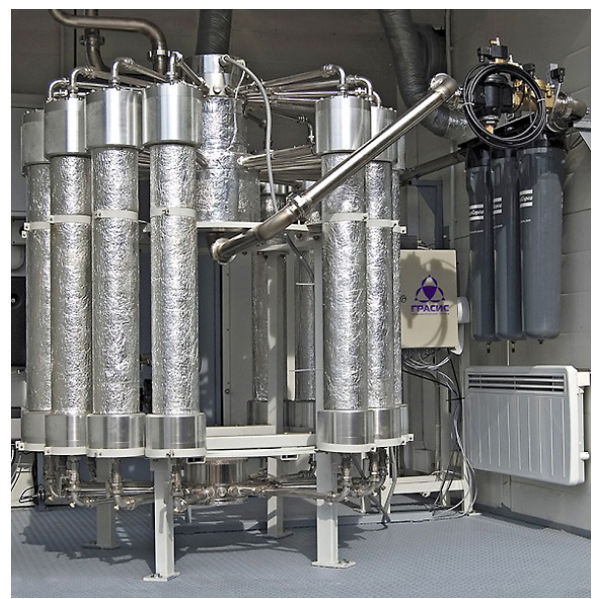

c)

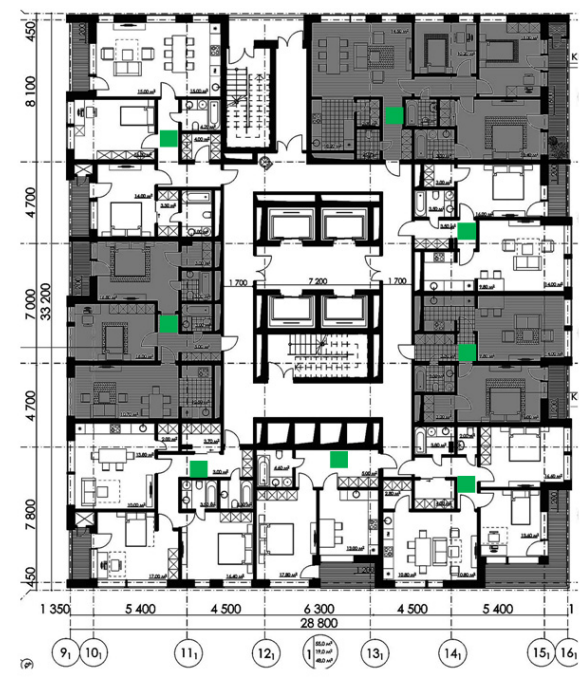

b)

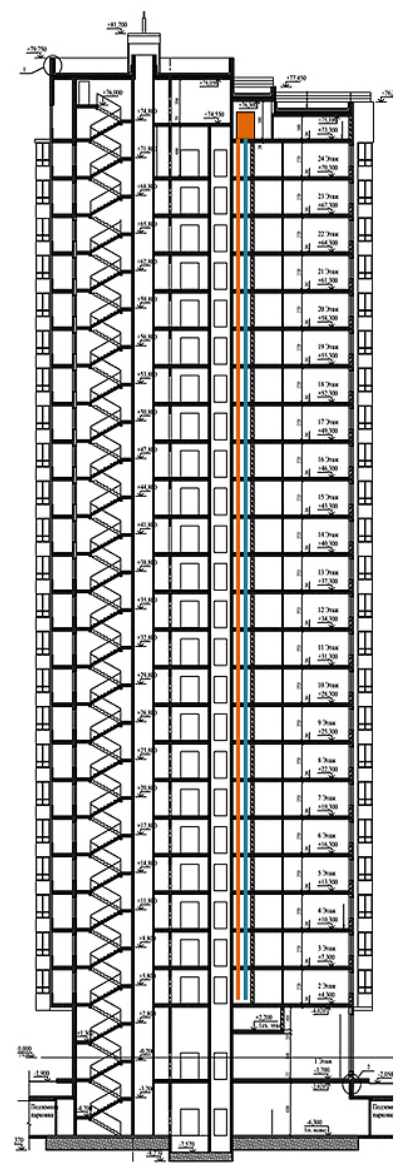

Fig. 7. MSA on the technical floor (a), section of a high-rise with nitrogen and air pipelines (b), floor layout with EGWMDS (c)

calculated by the controller (3), registered by the ADC (3.2) with a channel switch (3.1), or received from external counters, namely:

- of electricity corresponding to the PQI,

- of hot water (6) with "fair pay" in accordance with the actual range of temperature and according to the meter connected via the I/O port (3.9),

- of cold water according to the meter (7) through the same input-output port (3.9),

- of domestic gas according to the gas meter (8) connected through the input-output port (3.8).

Data transmission is carried out by the controller (3) to the appropriate supplying organizations and / and management companies, via a GSM radio modem (5), connected via the input-output port (3.10).

The controller (3) through the LCIP module (10) and the GSM radio modem (5) implements the following types of alarms and algorithms for their functioning:
- sound and LED flashing alert signals by the types of HFFE or accidents at the location of the EGWMDS (domestic gas leak, fire hazardous range of electricity consumption, power outage, water outages, etc.), which can be turned off with the "alert reset" button, if someone from the persons in the protected premises was able to take measures to eliminate the HFFE or an accident, while an SMS message will be sent to the owner of the protected premises and the management company without fail;

- audible and LED flashing warning signals by the types of HFFE at the location of the EGWMDS and the transmission of an SMS message with the receipt of its delivery in memory, in the absence of a "notification reset" after a set time interval (absence of persons in the protected premises or insufficient measures taken after the first "discharge"), in case of a domestic gas leak - to the gas emergency service and the owner, 


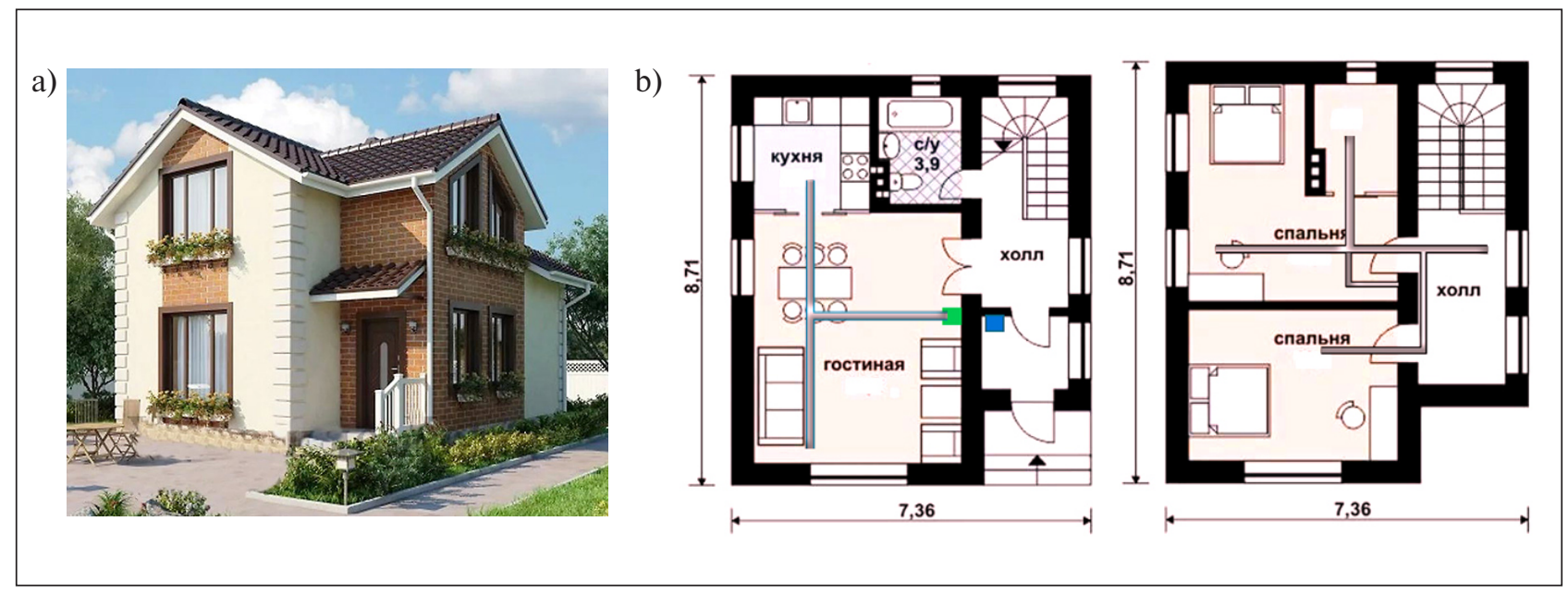

Fig. 8. Individual residential building (a) and floor plans with EGWMDS and TMSA (b)

to the management company and the owner, in case of a fire-threatening range of consumption / power outages - to the energy supervision, to the energy sales organization, to the management company and the owner, in case of fire (ignition plus evacuation) the fire brigade, the management company and the owner.

It is easy to see that the use of TMSA instead of MSA in an apartment or in an individual residential building occurs in a similar way [6].

The fundamental difference in the use of EGWMDS is the presence of an oxygen sensor in it, which allows monitoring its concentration, both in the absence of HFFE, and after their detection and switching on the MSA or TMSA to suppress them $[4,10]$.

It seems promising for further research and experiments on supplementing EGWMDS with a carbon dioxide sensor, which is also included in the HFF (Table 1), but not so much for detecting them [4], as for monitoring the living environment in an apartment / individual residential building, in order to create optimal living conditions, including control and management of heating [13, 14], as well as ventilation and air conditioning, taking into account energy saving and self-organization of safe life $[12,15]$.

From the point of view of the efficiency of using MSA [16], including mobile membrane units of various capacities [17], it is interesting the practice of Krasnodar Compressor Plant, LLC [18], in the provision of services for the use nitrogen to enterprises and organizations of the coal mining [19] and oil and gas industries [20], is interesting, incl. on hard-to-reach objects [21].

The fact is that both abroad and in our country for fire protection of various objects, incl. multi-apartment and high-rise residential buildings, they use the so-called dry pipes, which are a fire-fighting water supply system installed for large areas and where it is appropriate to keep the water pipe empty for reasons of economy, due to technical capabilities, or if the fire extinguishing composition can freeze, leading to pipe ruptures, which allows you to quickly, without laying hose lines, supply water from an arriving fire truck. In this case, without fail, dry pipes are installed [22, 23]:

- in multi-storey residential buildings with a height of 36 to $50 \mathrm{~m}$ or up to $75 \mathrm{~m}$ with fire hydrants in cupboards on each floor;

- in multifunctional buildings up to $50 \mathrm{~m}$ high with fire hydrants (libraries, administrative buildings, hotels, hospitals);

- with shut-off valves in attics and stairwells in twostorey buildings of the $\mathrm{V}$ degree of fire resistance with 4 or more apartments.

Taking into account the tendency for the construction of high-rise residential buildings with their grouping into microdistricts (Fig. 9), an idea arises,

firstly, instead of installing an MSA in every house, bring the "air" and "nitrogen" pipelines to the facade of the building, as is done for dry pipes [23];

secondly, to equip the fire brigades that guard such microdistricts with mobile nitrogen plants (Fig. 10), so that due to early and reliable detection of the HFF [10], at comparable times of "launching the MSA" and riding the combat crew to the object of the fire in the microdistrict, to save one-time and current costs for the installation and operation of "dozens of MSAs" in the buildings of the microdistrict.

It should be noted that LLC Krasnodar Compressor Plant jointly with the Don State Technical University, within the framework of the RF Government Decree No. 218, developed in 2013 a project for the production separators of air and the production of stationary and mobile fire protection equipment based on them, which, however, did not found support in the indicated competition [24]. 


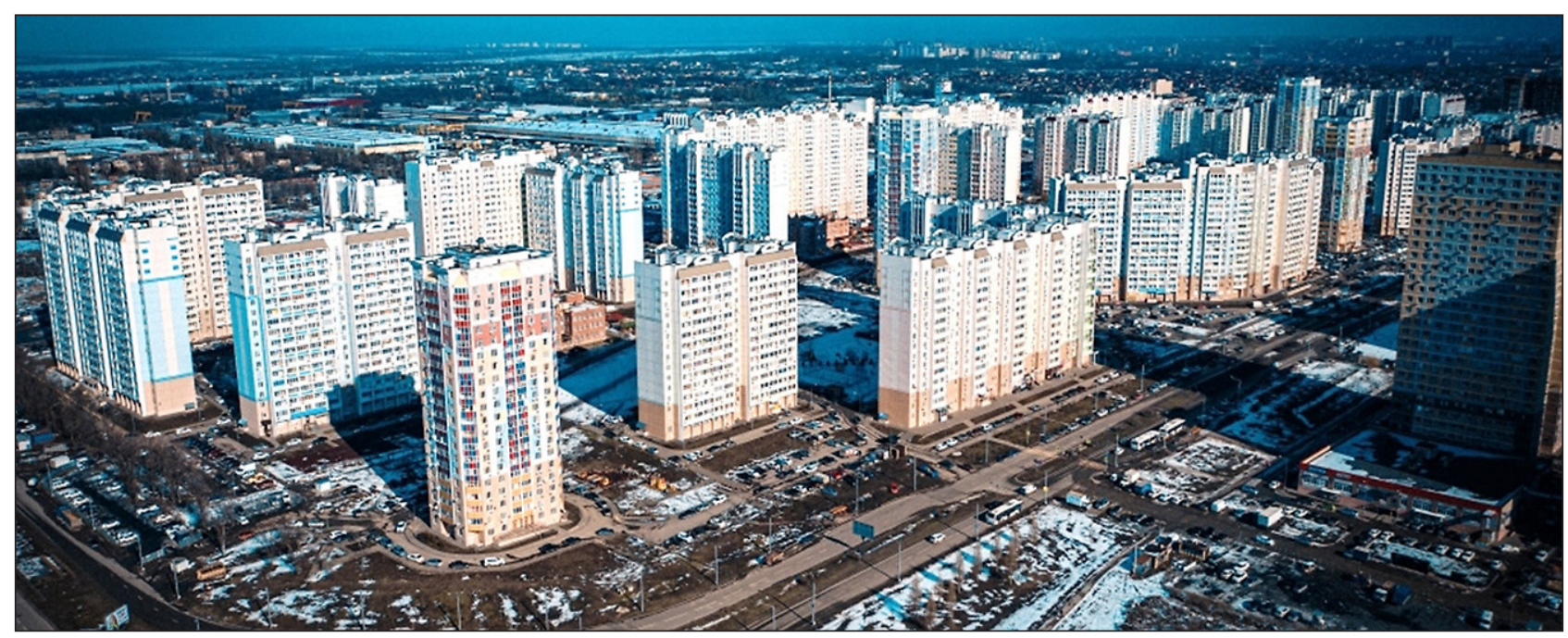

Fig. 9. Microdistrict Leventsovsky

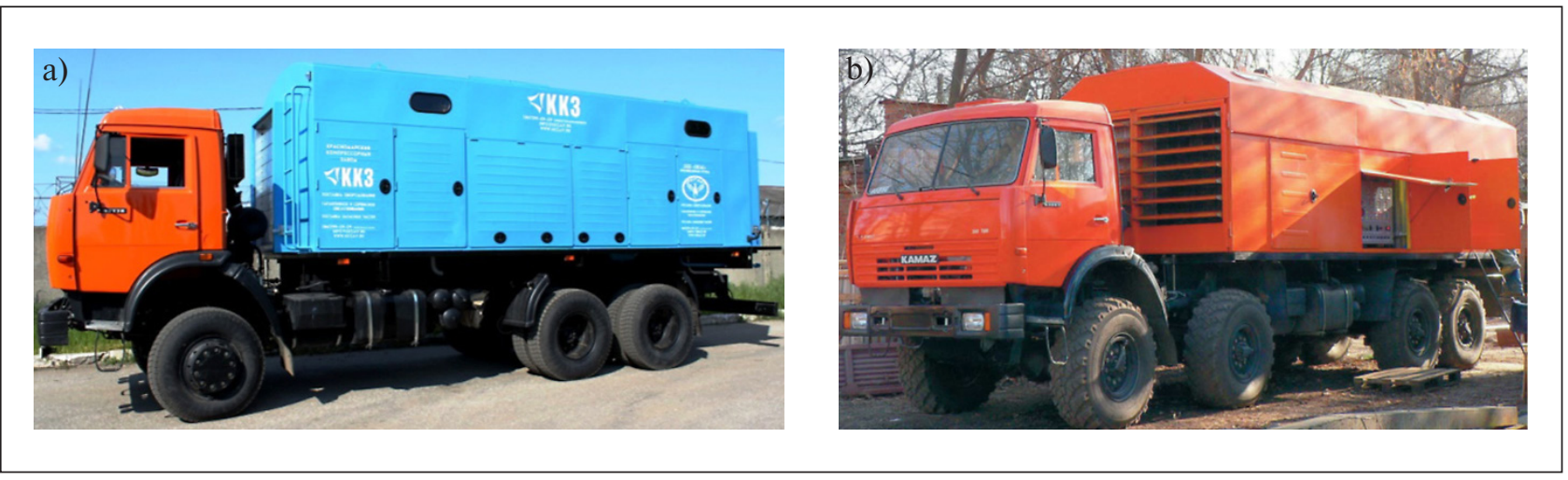

Fig. 10. Nitrogen station TGA-5/10 (a) and fire engine of Krasnodar Compressor Plant (b)

\section{CONCLUSION}

As a result of a systematic analysis of the problems of safe life in the residential sector (in apartments in residential buildings, in individual residential buildings) of cities and towns of the regions of Russia, fundamental shortcomings have been revealed in the organization and automation of accounting for consumed energy resources (electricity, gas, hot and cold water) in residential sector.

Based on the developed probabilistic-physical approach to the occurrence of fire-energy harm in the residential sector when electricity and gas are consumed, a consistent systemic synthesis of the methods and means for diagnosing fire-energy harm with nanotechnology of its suppression was carried out using an electric-gas-meter-detector-suppressor (reactive power compensation unit and air separation unit), which, together with membrane or thermomagnetic air separators, provide fire and explosion protection for an apartment / individual house.
Optimization and automation of hot and cold water metering was carried out, that resulted in developing a model of a universal electric-gas-water-meter-detectorsuppressor (EGWMDS) and a scheme of its use in apartments of residential buildings and in individual residential houses.

The proposed approach, according to the authors, is designed to "eliminate disorder" in the functioning of engineering systems in apartment buildings and individual residential houses, as well as to carry out optimal automation of the life support of the residential sector, regardless of the structures of resource-supplying / management companies and territorial emergency and supervisory services.

The developed method and EGWMDS make it possible in the shortest possible time to implement it using the reinvestment model of the system of adaptive fire and energy taxation of individuals in the residential sector $[6,10,11]$.

Studies have shown that the proposed approach can be implemented at the objects of trade, health care, education, science and culture [2, 12, 24]. 
The paper "Nanotechnologies of "intellectualization" of energy accounting and of suppression of fire-energy harm in engineering systems of residential buildings. Part 1" was published in "Nanotechnologies in Construction" 2021; 13(2). Available from: doi: 10.15828/2075-8545-2021-13-2-95-107.

\section{REFERENCES}

1. Korneev V. Domestic gas explosions in residential buildings in Russia in 2016. Dossier. TASS: Russian news agency. 2016. Available from: http://tass.ru/info/3727196.

2. Belozerov V.V. On the cognitive model of safety management of objects with a mass presence of people (based on the results of the examination of the fire of the market "Turgenevsky"). Security Issues. 2018; 5: 35-62. Available from: doi: 10.25136/2409-7543.2018.5.27485.

3. Gas meters Grand-SPI. Operation manual: TUAS.407299.002 RE. Rostov-on-Don: LLC Turbulence Don; 2015.

4. Belozerov V.V., Belozerov V.V., Dolakov T.B., Nikulin M.A., Oleinikov S.I. Nanotechnology of "intellectualization" of energy accounting and suppression of fire and energy harm in engineering systems of residential buildings (part 1). Nanotechnologies in Construction. 2021; 13(2): 95-107. Available from: doi: 10.15828/2075-8545-2021-13-295-107.

5. Dolakov T.B., Oleinikov S.N. Model of an automated microsystem for accounting for energy resources and fire and explosion protection of the residential sector. Electronics and electrical engineering. 2018; 2: 48-72. Available from: doi: $10.7256 / 2453-8884.2018 .2 .26131$.

6. Belozerov V.V., Dolakov T.B., Oleinikov S.N., Perikov A.V. Synergetics of life safety in the residential sector. Moscow: Publishing house of the Academy of Natural Sciences; 2017. Available from: doi: 10.17513/np.283.

7. Voroshilov I.V., Maltsev G.I., Koshakov A.Yu. Nitrogen generator. RF Patent No. 2450857. 2010-24-08.

8. Belozerov V.V., Barefoot S.I., Videtskikh Yu.A., Novakovich A.A., Pirogov M.G., Tolmachev G.N. A method of thermomagnetic air separation and a device for its implementation. RF Patent No. 2428242. 2011-10-09.

9. Water meter Grand SV TLM: Operation manual. TUAS.407212.001 RE - Rostov-on-Don: LLC Turbulence Don, 2012.

10. Belozerov V.V., Denisov A.N., Dolakov T.B., Voroshilov I.V., Nikulin M.A., Oleinikov S.N., Belozerov Vl.V. A method for early and reliable detection of hazardous fire factors with suppression of fire and electrical harm in residential premises. Application for invention No. 2021112049. 2021-27-04.

11. Belozerov V.V., Oleinikov S.N. On the issue of an adaptive fire and energy tax in ensuring fire safety. Improvement of the theory and methodology of finance and taxation: Proceedings of international scientific and practical conference. Volga Research Center. Yoshkar-Ola: Colloquium; 2012. P. 106-111.

12. Belozerov V.V. Synergetics of safe life. Rostov-on-Don: SFedU; 2015.

13. Belozerov V.V., Dolakov T.B., Belozerov V.V. On safety and prospects of electrical heating in individual residential houses. Modern science-intensive technologies. 2017; 11: 7-13.

14. Belozerov V.V., Seryachenko M.V. Model of a local automated control system for heat and water supply in the residential sector. In: N.A. Shevchenko (ed.) Actual problems of science and technology 2020: Materials of the national scientific-practical conference. Rostov-on-Don: DSTU; 2020. P. $27-28$.

15. Belozerov V.V. "Intelligent" ventilation and air conditioning system in apartments of multi-storey buildings and in individual residential buildings with nanotechnology for protection against fires and explosions. Nanotechnologies in Construction. 2019; 11(6): 650-666. Available from: doi: 10.15828/2075-8545-2019-11-6-650-666.

16. Voroshilov I.V., Melnik A.V., Shuleikin P.B. High pressure nitrogen for enhanced oil recovery: new generation TGA stations set energy efficiency records. Oil. Gas. Innovations. 2020; 10(239): 41-46.

17. Voroshilov I.V., Anisimov K.V., Shuleikin P.B. The use of nitrogen compressor stations TEGAS in the oil industry. Sfera. Oil and Gas. 2018; 6(68): 92-94.

18. Voroshilov I.V., Kalyuzhnaya Yu.S. TEGAS: Rent of compressor stations is an established trend. Drilling and oil. 2014; 9: 79-80.

19. Voroshilov I.V., Vladykin D.V. Promising methods of mining methane from coal seams, ensuring the safety of miners. Coal. 2008; 6(986): 22-23.

20. Voroshilov I.V., Kopachev D.N., Kalyuzhnaya Yu.S. Application of compressor and gas separation equipment "TEGAS" in oilfield services. Drilling and oil. 2014; 5: 59-60. 
21. Voroshilov I.V. Mobile nitrogen compressor stations TGA - operational provision of hard-to-reach objects with compressed nitrogen. Exposition Oil Gas. 2012; 4 (22); 74-75.

22. Ministry of Emergency Situations of Russia. SP 8.13130. Fire protection systems. Outdoor fire-fighting water supply. Fire safety requirements. 2020.

23. Ministry of Emergency Situations of Russia. SP 10.13130. Fire protection systems. Internal fire-fighting water supply. Norms and rules of design. 2020.

24. Voroshilov I.V., Meskhi B.Ch., Prilutsky A.I. Development and putting into production of air separators and production of fire protection means based on them (project No. 2013-218-04-023). Electronics and electrical engineering. 2016; 1: 21-71; Available from: doi: 10.7256/2453-8884.2016.1.21034.

\section{INFORMATION ABOUT THE AUTHORS}

Valery V. Belozerov, Dr. Sci. (Eng.), Associate Professor, Professor of the Department of "Automated Control Systems" FSBEI HE "Don State Technical University", Rostov-on-Don, Russia, ORCID: https://orcid.org/0000 -0001-6999-7804, e-mail: safeting@mail.ru

Igor V. Voroshilov, Cand. Sci. (Phys.-Math.), General Director of Krasnodar Compressor Plant LLC, Krasnodar, Russia, ORCID: https://orcid.org/0000-0002-6546-1700, e-mail: gendir@kkzav.ru

Alexey N. Denisov, Dr. Sci. (Eng.), Professor of the Department of Fire Tactics, Federal State Budgetary Educational Institution of Higher Education "Academy of State Fire Service" EMERCOM of Russia, Moscow, Russia, ORCID: https://orcid.org/0000-0003-2594-9389, e-mail: dan_aleks@mail.ru

Mikhail A. Nikulin, Senior Lecturer, Department of Technosphere Safety, State Agrarian University of the Northern Trans-Urals, Tyumen, Russia, ORCID: https://orcid.org/0000-0002-7756-3456, e-mail: pojar_2003@mail.ru

Sergey N. Oleinkov, Cand. Sci. (Eng.), Deputy Head of the Faculty of Training Scientific and Pedagogical Personnel, Academy of State Fire Service of the Ministry of Emergency Situations of the Russian Federation, Moscow, Russia, ORCID: https://orcid.org/0000-0002-8316-075X, e-mail: osn-fire@bk.ru

\section{Authors declare the absence of any competing interests.}

Received: 15.03.2021.

Revised: 04.04.2021.

Accepted: 08.04.2021. 